\title{
A SMART SYSTEM OF AC MOTOR SPEED CONTROL BASED ON ROOM TEMPERATURE
}

\author{
Shishir Chandra ${ }^{1}$, P. Vivek ${ }^{2}$, A. Kumar \\ ${ }^{1} 8^{\text {th }}$ Sem, Department of EEE, BNMIT,Bangalore-70, Karnataka, India \\ ${ }^{2} 8^{\text {th }}$ Sem, Department of EEE, BNMIT,Bangalore-70, Karnataka, India \\ ${ }^{3}$ Associate Professor, Department of EEE, BNMIT, Bangalore-70, Karnataka, India
}

\begin{abstract}
In the engineering world, every day, new and different applications for an AC motor are developed, clarifying the need and dependency on such machines in our society. Also at the same time, due to their increasing necessity, better energy efficient operating methods have to be developed for such motors. While coming to their operation, it can be clearly identified that the control of their speed during real time operations is a major characteristic of their energy usage. Hence, the speed at which the motor runs at a given load determines the energy efficiency and in turn overall efficiency. Evidently, certain methods have to be devised to regulate the speed of the motor $(A C)$ for better energy utilization. This paper talks of one such method which is used to regulate speed of the motor using the principle of varying the input voltage to the motor based on ambient temperature. Of the many parameters that influence motor performance, Temperature of the ambient is the most important deciding factor. Also, in domestic applications or in Electronic Equipment, Cooling fans are a major requirement. These Fans operate based on the temperature of its surroundings. Hence, in such cooling systems efficiency of energy can be improved by designing a control that provides a temperature dependant operation. In this paper, temperature control of an AC motor is obtained by controlling a HBridge inverter through a microcontroller device, which produces appropriate pulse signals corresponding to the temperature of the surroundings. The control signal fed-inverter gives out temperature equivalent AC voltage output which is fed to the AC motor, therefore, achieving a smart energy efficient control for Modern motors.
\end{abstract}

Keywords: SPWM (Sinusoidal Pulse Width Modulation), SPIM( single phase induction motor), MOSFET(Metal Oxide Semi-conductor Field Effect Transistor),H-bridge, Arduino.

\section{INTRODUCTION}

Single phase induction motors are the most commonly used and readily accepted machines for usage in Domestic, Commercial and Industrial Applications.

The main objective is to design and develop an Arduino based motor control for its automatic speed control based on ambient temperature. This design is mainly applied to a single phase induction motor which will function automatically in adjusting the speed according to the ambient room temperature [1]. This methodology intends to eliminate manual control and incorporate automatic control resulting in energy saving as the speed of the motor depends on the ambient temperature and hence at low temperatures no extra power is needed to drive the motor at higher speed unnecessary [2]. Arduino was preferred to reduce the hardware complications involved in the control circuit and for its simplicity.

Nowadays, due to the advancement of the power electronic switches, the flow of alternating or direct power to the motor can be controlled by the simple switching actions of the power switches (MOSFET, IGBT, IGCT, etc.). In recent times, remarkable efforts have been made in speed control of single phase induction motor (SPIMD) drives.Different types of SPWM strategies have been used for speed control of induction motor drives [3]. By using SPWM strategies for the inverter, driving of the induction motor is possible with lower harmonic levels. Motor speed sensing system uses a temperature sensor LM35[4].

\section{DESIGN}

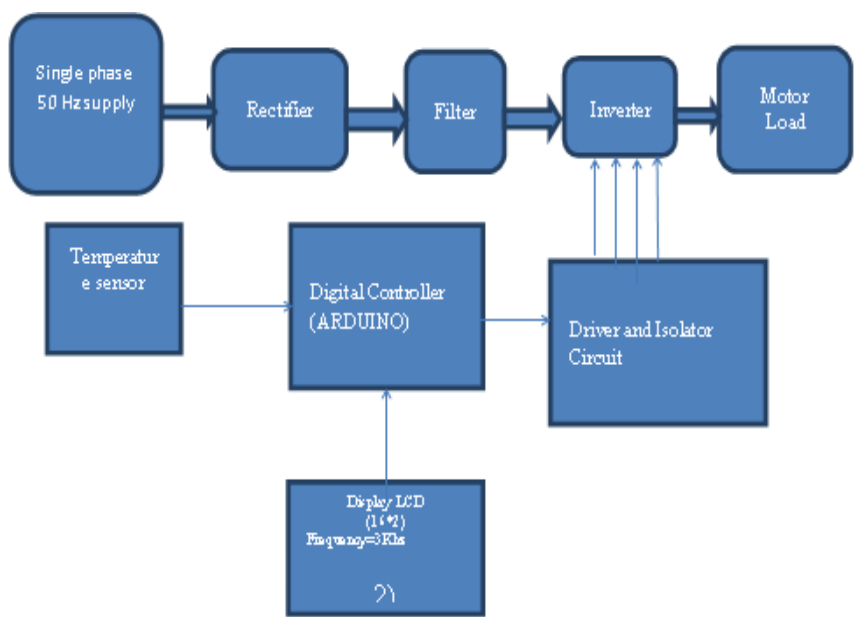

Fig-1: Complete Block Diagram

The Proposed system was designed and developed in order to cater the requirements of automatic speed control of $\mathrm{AC}$ Motor. 
The block diagram for the proposed system is shown in fig 1. It constitutes of two parts: Power Circuit and Control Circuit. The output of the sensor is then fed to Arduino. These output signals will then be sent to the gates of the MOSFETs to control the inverter output.

Explaining the control stage wise, the Temperature sensor [5] reads the temperature of its surroundings and produces an appropriate analogue voltage which is sent to the analogue pin of the Arduino microcontroller. Based on the code downloaded into the Arduino and the temperature presettings defined in the logic, it converts the temperature equivalent voltage of the sensor into temperature in Celsius or in any relevant scale and stores the value in a memory location. The Arduino will generate the desired pulse signals which are correspondent to the temperature value stored, by considering pre-set values. Based on this, two appropriate out of phase pulse signals are produced at the designated output pins.

The pulse signals are fed to the inverter through an isolator and driver circuits which are used for isolation of low power control circuit from the high power inverter circuit. The inverter being fed DC power from an uncontrolled rectifier, produces the corresponding output voltage which is fed to the AC motor. Therefore, the average power supply to the motor will be varied; hence, automatic speed regulation is achieved

\subsection{Preliminary Assumption and Analysis for SPWM Pulse Signals}

Certain Prerequisites and assumptions are needed to understand and then implement the generation of SPWM pulses.

Assuming, Pulse Width Modulation to be $3 \mathrm{KHz}$.

Thus,

Time Period $=1 / 3 \mathrm{~K}=334$ microseconds.

Therefore,

No. of pulses $=10$ milliseconds/ 334microseconds.

$=30$ pulses for each cycle in 10 milliseconds.

Therefore, Pulse Width is dependent on sin $\omega t$, duty cycle for each of the 30 PWM pulses varies depending on sin $\omega t$.

Now, Pulse Angle = 180 degrees 30 degrees .

$=6$ degrees.

Therefore, Pulses are produced at: 6 degrees, 12 degrees, 18 degrees 180 degrees.

The total numbers of pulses generated are 30 .

\subsection{Working}

\section{At 6 degrees:}

$Y=\sin 6$

Thus, $\mathrm{Y}=0.1045$

Now, ON Period $=\mathrm{Y} * 334=34.19$ microseconds

OFF - Period $=334-34.91=299.087$ microseconds

\section{At 12 degrees:}

$\mathrm{Y}=\sin 12$

Thus, $\mathrm{Y}=0.2079$

Now, ON Period is $=\mathrm{Y}^{*} 334=69.44$ microseconds

OFF Period $=334-69.44=266.56$ microseconds

The table representing the $\mathrm{ON}$ and $\mathrm{OFF}$ period at each pulse angle is represented in the table-1

Table-1: ON and OFF Period at each Pulse Angle

\begin{tabular}{|c|c|c|}
\hline Degrees & ON period $(\mu S)$ & $\begin{array}{l}\text { OFF } \\
\operatorname{period}(\mu S)\end{array}$ \\
\hline 6 & 34.912 & 299.08 \\
\hline 12 & 69.44 & 264.55 \\
\hline 18 & 103.211 & 230.78 \\
\hline 24 & 135.85 & 198.14 \\
\hline 30 & 167 & 167 \\
\hline 36 & 196.32 & 137.67 \\
\hline 42 & 2234 . & 110.51 \\
\hline 48 & 248.21 & 85.78 \\
\hline 54 & 270.21 & 63.788 \\
\hline 60 & 289.25 & 44.74 \\
\hline 66 & 305.124 & 28.875 \\
\hline 72 & 317.65 & 16.34 \\
\hline 78 & 326.701 & 7.298 \\
\hline 84 & 332.17 & 1.829 \\
\hline 90 & 334 & 0 \\
\hline
\end{tabular}

\section{CIRCUIT DIAGRAM}

The Arduino microcontroller is used for the implementation of generation of SPWM pulses with temperature control. The control circuit comprises mainly of Arduino UNO and the temperature sensor. The main control of the power circuit is based on the circuit shown in fig-2a which is the core of the whole circuit, this is where control pulses are generated according to the varying temperature. Arduino UNO makes use of the microcontroller ATMEGA 328P-PU. The pulses are produced based on the algorithm given in 3.1.

Isolator used in the circuit is MCT2E which is an optoisolator. The driver used in the circuit is TC4424. Fig-2b shows the power circuit consisting a bridge rectifier connected to an H-Bridge inverter through a filter. The inverter output can also be filtered and fed to the motor load 


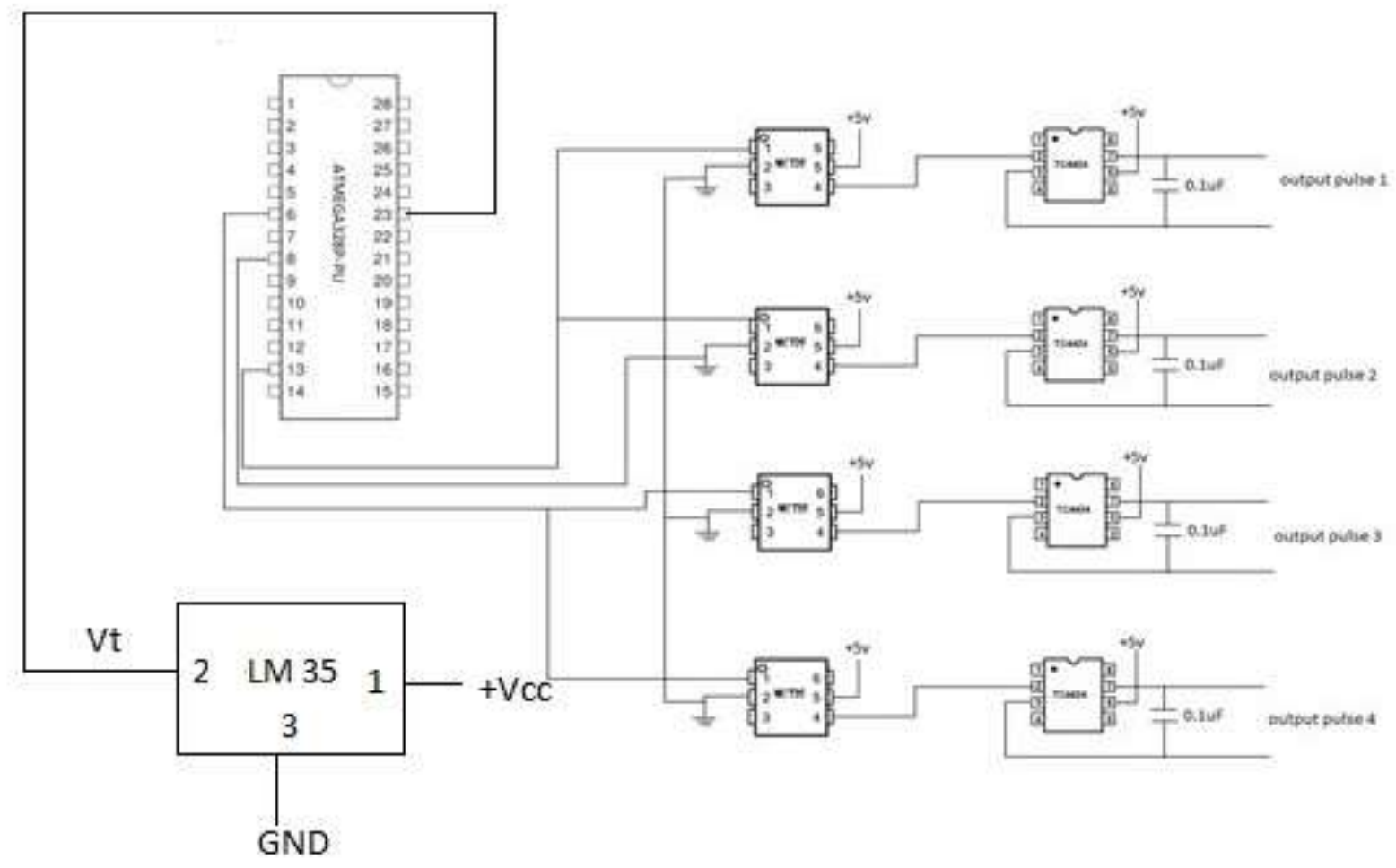

Fig-2a: Control Circuit Diagram

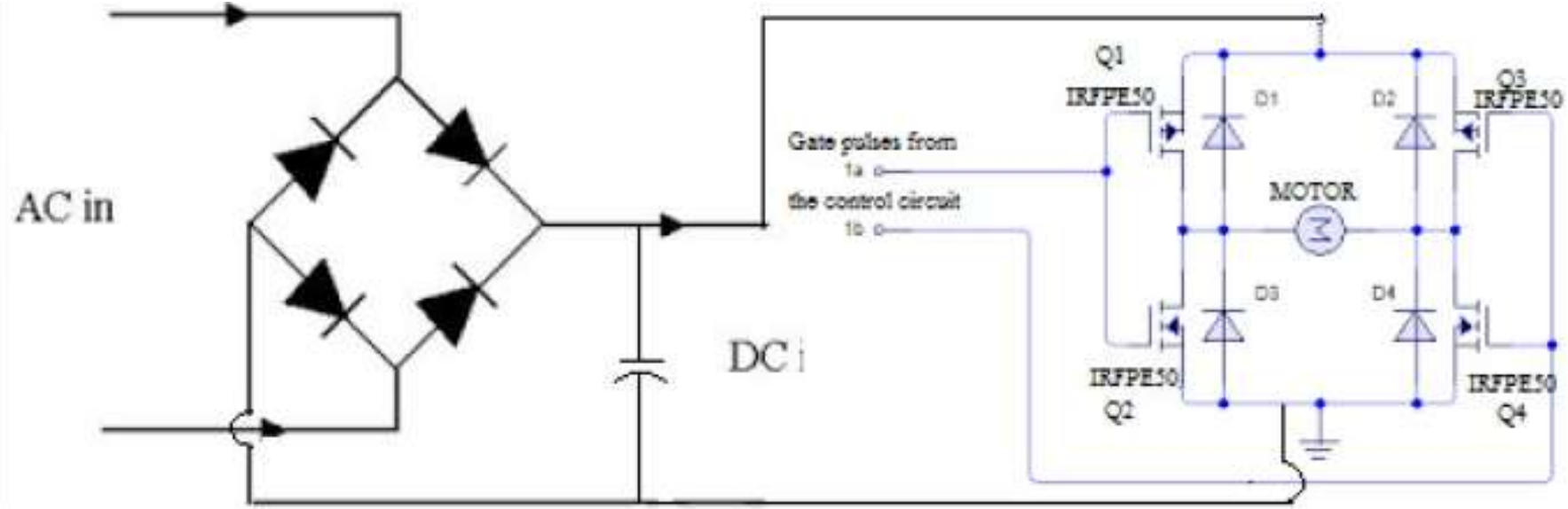

Fig-2b: Power Circuit Diagram

\subsection{Algorithm}

The following algorithm was designed to obtain temperature dependant SPWM pulses:

Step 1: Start.

Step 2: Initialise the required variable and call the necessary libraries (for LCD).

Step 3: Read the voltage value from the temperature sensor.

Step 4: Convert the voltage value into temperatures, preferably in Celsius.

For Celsius,

$\mathrm{T}_{\mathrm{c}}=(500 * \mathrm{~V}) / 1023$

For Fahrenheit,

$\mathrm{T}_{\mathrm{f}}=\left(\left(9 * \mathrm{~T}_{\mathrm{c}}\right) / 5\right)+32$
Step 5: Print or display temperature value on the LCD.

Step 6a: If the temperature (in degree Celsius) is more than 35 degree Celsius, allocate 1 on

Specified variable (say $\mathrm{x}$ ).

Step 6b: If the temperature (in degree Celsius) is less than 15 degree Celsius, allocate 0 in theVariable (x).

Step 6c: Else If the temperature (in degree Celsius) is less than 35 degree Celsius and greater than 30 degree Celsius, allocate 0.8 in the variable $(\mathrm{x})$.

Step 6d: Else If the temperature (in degree Celsius) is less than 30 degree Celsius and greater than 25 degree Celsius, allocate 0.6 in the variable $(\mathrm{x})$. 
Step 6e: Else If the temperature (in degree Celsius) is less than 25 degree Celsius and greater than 20 degree Celsius, allocate 0.4 in the variable $(\mathrm{x})$.

Step 6f: Else If the temperature (in degree Celsius) is less than 20 degree Celsius and greater than 15 degree Celsius, allocate 0.2 in the variable (x).

Step 7: Initialize an array (duty cycle array) containing the 30 values which are sine of pulses angle values starting from 6 degrees, 12 degrees, ..., 90 degrees, 84 degrees, 78 degrees ... to 6 degrees.

Step 8: Create another array (t [ ]), whose values are initialised as, $\mathrm{t}$ [ element ] $=(\mathrm{x} * 0.9 *$ duty cycle $)$ [element] *334.

Step 9: Assign respective pins (13 and 6) as output pins.

Step 10a: For a value of a variable (say i) from 0 to 30 . Write a HIGH on pin 13 for $\mathrm{t}$ [i] Microseconds.

Step 10b: Write a LOW on pin 13 for $334-\mathrm{t}$ [i] microseconds.

Step 10c: Increment i by 1 .

Step 11a: For a value of a variable (say i) from 0 to 30 , write a HIGH on pin 6 for $\mathrm{t}$ [i] Microseconds.

Step 11b: Write a LOW on pin 6 for $334-\mathrm{t}$ [i] microseconds.

Step 11c: Increment I by 1.

Step 12: Go to step 10.

\section{IMPLEMENTATION AND RESULTS}

\subsection{Hardware Implementation}

All the above designs were brought together to implement in reality, the required objective. As a result a circuit is being rigged to realize the design is as shown in Figure-4. The system was tried for three different and feasible temperatures and its corresponding results were tabulated. The change in speed proportionally to the change in room temperature and its calibration by practical observation is as shown in the table- 2 . The table- 2 signifies the required result of variation in the speed of the motor when the surrounding temperature varies. Figure-3 shows the graphical representation of the variation of speed with temperature when tested using the hardware implemented.

Table -2: Temperature v/s speed calibration result

\begin{tabular}{|l|l|}
\hline Temperature (degree Celsius) & Speed (rpm) \\
\hline 19 & 295 \\
\hline 23 & 605 \\
\hline 28 & 930 \\
\hline 32 & 1360 \\
\hline 37 & 1750 \\
\hline
\end{tabular}

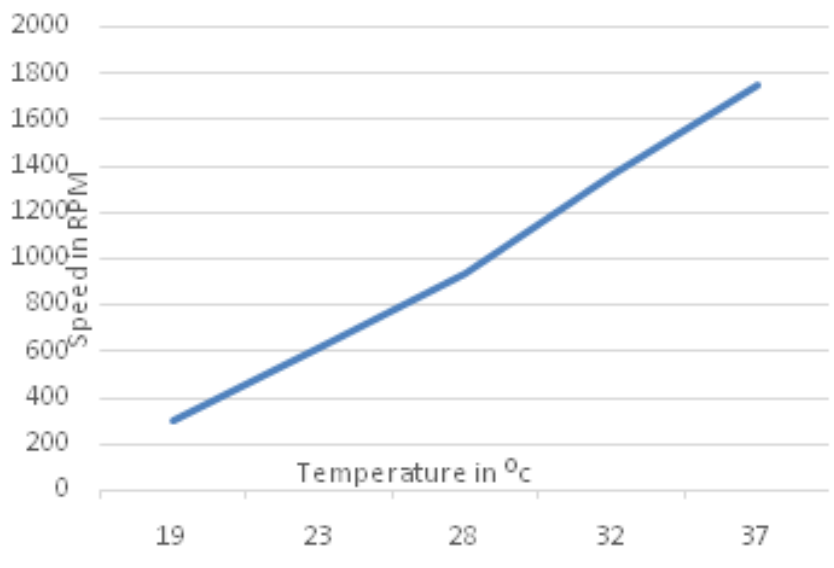

Fig-3: Speed vs Temperature Curve

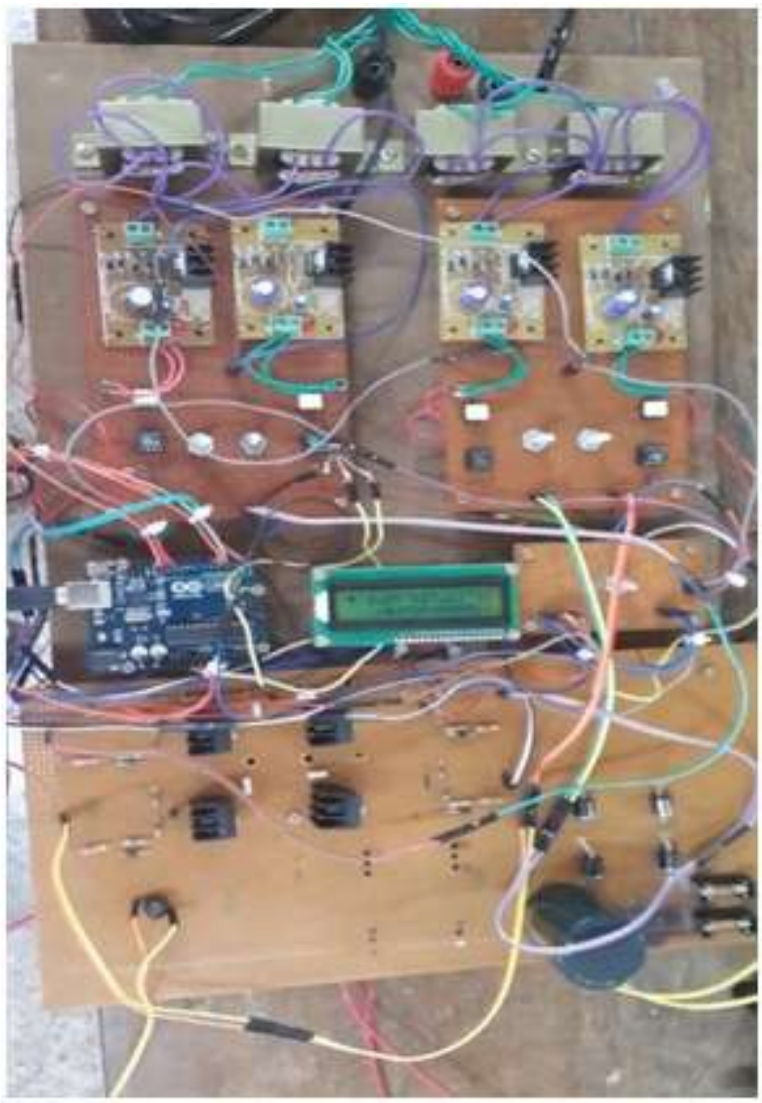

Fig -4: Complete Hardware circuit

\section{CONCLUSION}

The use of a temperature based variable speed drive for speed control application usually offers an energy efficient alternative and an economical solution. Basic Variable Speed Drives, such as SPWM inverter drives are used where the required speed control needs to be accurate. The compact inverter has its hardware reduced to a minimum through the use of H-bridge inverter circuit. This proposed variable speed drive control with voltage control method will offer cost effective and smart solutions for commercial and consumer applications. 
This concludes that a single-phase induction motor can be successfully operated from a variable voltage amplitude control and the motor's speed can be easily varied by implementing the drive system devised based on ambient temperature. The experiments results obtained using the proposed drive system proves the simplicity in the speed control of the single phase induction motor.

The wide range of applications are endless as smart control of electronics are at the epitome of growth, driven by the strong consumer and industrial demand, the need for automated technology has never been better. The possible implementations of the temperature controlled motor are as expressed below

1) Fans in Domestic and Commercial Applications.

2) For cooling of machines.

\section{REFERENCES}

[1]. National Power \& Energy Conference (PECon) 2004 Proceedings, Kuala Lumpur, Malaysia 121Speed Drive of Single-phase Induction Motor, Hamad S. H; S. M. Bashi, I. Aris and N.F.Marlah .

[2]. International Journal of Advanced Research in Electrical, Electronics and Instrumentation Engineering, Vol. 2, Issue 7, July 2013, Copyright to IJAREEIE www.ijareeie.com 3470Design, Modelling and Simulation of a Microcontroller Based Temperature Control in a Ventilation System, K.A Akpado1, C.O Ezeagwu2, A. Ejiofor3, A.O Nwokeke.

[3]. Analysis of Single-Phase SPWM Inverter;A Thesis Submitted In partial fulfilmentof the requirementsfor the degree of Bachelor in Electrical Engineering ByBijoyprakashMajhiUnder the supervision ofProf.SomnathMaity .

[4]. International Journal of Innovative Research in Science, Engineering and Technology Vol. 4, Issue 7, July 2015 Copyright to IJIRSET .Design and Fabrication of Temperature based DC Fan Speed Control System using Microcontroller and Pulse Width Modulation Technique Surabhi1, Upendra Prasad2, Vivek Kumar Jain3

[5]. 6th Int'1 Conference on Electrical, Electronics \& Civil Engineering (ICEECE'2014) Nov. 27-28, 2014 Cape Town (South Africa) Automatic Fan Speed Control System Using Microcontroller Mustafa Saad, Hossam Abdoalgader, and Muammer Mohamed

\section{BIOGRAPHIES}

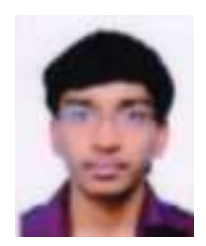

Shishir Chandra, $8^{\text {th }}$ sem, Department of EEE , BNMIT , Bangalore-70.

Email:shishirchandra1994@gmail.com

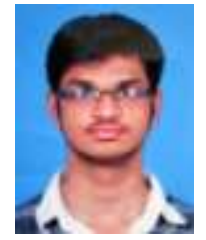

P.Vivek , $\mathbf{8}^{\text {th }}$ sem, Department of EEE, Student, BNMIT , Bangalore - 70 Email: pathipati.vivek@gmail.com
A.Kumar, Associate Professor , Department of EEE, BNMIT , Bangalore - 70

Email: kumar_1970@hotmail.com 